\title{
An "interaction-mediating" strategy towards enhanced solubility and redox properties of organics for aqueous flow batteries
}

Zhifeng Huang a,b, Christopher W. M. Kay c,d , Björn Kuttich e, Daniel Rauber a , Tobias Kraus ${ }^{\mathrm{c}, \mathrm{e}}$, Hongjiao $\mathrm{Li}^{\mathrm{f}}$, Sangwon Kim ${ }^{\mathrm{b}}$, Ruiyong Chen ${ }^{\mathrm{a}, \mathrm{b}, *}$

${ }^{\text {a }}$ Transfercenter Sustainable Electrochemistry, Saarland University, 66125 Saarbrücken, Germany

${ }^{\mathrm{b}}$ Korea Institute of Science and Technology (KIST) Europe, 66123 Saarbrücken, Germany

${ }^{\mathrm{c}}$ Department of Chemistry, Saarland University, 66123 Saarbrücken, Germany

${ }^{\mathrm{d}}$ London Centre for Nanotechnology, University College London, 17-19 Gordon Street, London WC1H 0AH, United Kingdom

${ }^{\mathrm{e}}$ INM-Leibniz Institute for New Materials, 66123 Saarbrücken, Germany

${ }^{\mathrm{f}}$ Institute of Nanotechnology, Karlsruhe Institute of Technology, 76021 Karlsruhe, Germany

* Corresponding author.

E-mail address: ruiyong.chen@uni-saarland.de; hc18chen@gmail.com (R. Chen)

Abstract: Aqueous redox flow batteries using electroactive organic materials are currently attracting significant attention. However, the influence of supporting electrolytes on the aqueous solubility, electrochemical reversibility and chemical stability of the organic components has rarely been investigated. Here, a new electrolyte design strategy towards enhanced solubility and chemical stability of active materials is proposed by using interaction-mediating species. 3 molality aqueous imidazolium chlorides, with high ionic conductivity and water-like flowability, enable a record aqueous solubility of $4.3 \mathrm{M}$ for a commercially available nitroxyl radical and reversible $2 \mathrm{e}^{-}$reaction of unmodified methyl viologen at moderate concentrations. With $0.6 \mathrm{M}$ electrolyte, flow cell shows remarkable chemical stability of the nitroxyl radical, excellent cycling stability over 250 cycles at $80 \mathrm{~mA}$ $\mathrm{cm}^{-2}$, and a peak power density of $121.6 \mathrm{~mW} \mathrm{~cm}^{-2}$ at $175 \mathrm{~mA} \mathrm{~cm}^{-2}$. Furthermore, nitroxyl radical catholyte with a concentration of $3 \mathrm{M}$ is tested in a flow cell. It maintains an impressive steady energy efficiency of $65 \%$ at $30 \mathrm{~mA} \mathrm{~cm}^{-2}$. This work paves a new way for the development of high performance aqueous electrolytes based on organic materials.

Keywords: aqueous redox flow batteries, supporting electrolytes, ionic liquids, redox-active organic materials, EPR spectroscopy 


\section{Introduction}

The increasing uptake of renewable energy requires the development of large-scale energy storage technologies to provide backup power and to stabilize the power output [1-3]. Recently, redox flow batteries (RFBs) using water-soluble, organic redox-active compounds as alternatives to metal-based materials have drawn substantial attention as a promising stationary energy storage technique with merits such as low cost, non-flammability, structural tunability and essentially unlimited availability of active materials [4-14]. However, a recognised challenge is their low energy density compared to other types of rechargeable batteries due to the limited solubility of organic molecules in aqueous media. In addition, the chemical instability of organic materials in aqueous media hinders their practical applications.

Novel electrolyte designs for RFBs including molecular engineering [8,10,11,15], suspension of solid materials [16,17] and the concept of redox-targeting [18-20] have been reported to improve the content (in soluble or solid form) of redox-active materials. Additionally, concentrated eutectic electrolytes and liquid organic molecules with solvent-free or low fraction of solvents have been reported [21-28]. However, these commonly display high viscosity and insufficient ionic conductivity and thus the reported operating current densities were relatively low $\left(<1 \mathrm{~mA} \mathrm{~cm}^{-2}\right)$. In electrolytes, the organic active species exist as uncharged molecular solutes or ionic solutes and may change its form upon electrochemical reactions. Ionic organic solutes can provide sufficient water solubility, as has been often used in the strategy of ionic modification [29-37], whereby, ionic grafting with hydrophilic groups leads to improved chemical stability and can be used to control the redox potential [38-41]. In contrast, the organic molecular solutes that appear in aqueous electrolytes should form hydrogen bonds with water molecules to remain as liquid form, otherwise, their solubility limits are reached. The commonly used conducting ions in aqueous electrolytes, such as $\mathrm{H}^{+}$, $\mathrm{Na}^{+}, \mathrm{K}^{+}, \mathrm{OH}^{-}$and $\mathrm{Cl}^{-}$etc. hardly affect the solubility and especially the electrochemical properties of organic materials. To date, a rational selection of $\mathrm{pH}$ neutral supporting electrolytes for promoting the physiochemical and electrochemical performance of organic materials has only rarely been explored. An ideal conducting ionic species in electrolytes should have high ionic conductivity, low viscosity and importanly impose strong interactions on the organic solutes [41]. 
Inspired by the powerful dissolution capability of imidazolium chlorides to organic compounds and polymers [14], and our previous work for using "water-in-ionic liquids" to obtain broad electrochemical and temperature stability of aqueous electrolytes [42-44], herein, we describe aqueous imidazolium chlorides as supporting electrolytes to boost the properties of organic active materials in aqueous RFBs for the first time. Two well-established commercial organic materials, 4-hydroxy-2,2,6,6-tetramethylpiperidine 1-oxyl (4-OH-TEMPO) and methyl viologen dichloride (MV), were selected as model compounds without further chemical modification.

Significantly, a record aqueous solubility of $4.3 \mathrm{M}$ for 4-OH-TEMPO catholyte was achieved, compared to $2.1 \mathrm{M}$ in pure water, arising from a strong interaction between the imidazolium cations and the nitroxyl radicals. In addition, compared to conventional aqueous $\mathrm{NaCl}$ supporting electrolyte, the redox potential of the 4-OH-TEMPO can be shifted to more positive value in our aqueous imidazolium chlorides. Moreover, for the MV anolyte, highly reversible $2 \mathrm{e}^{-}$reactions are accessible at a moderate concentration of MV by simply using our proposed supporting electrolytes. Such behavior is distinct from the MV tested in aqueous $\mathrm{NaCl}$. Flow cell, by combing the 4-OH-TEMPO catholyte and MV anolyte, exhibited two pairs of well-defined charge/discharge plateaus with a high Columbic efficiency (CE) of $99.0 \%$ at $55 \mathrm{~mA} \mathrm{~cm}^{-2}$. By increasing the electrolyte concentration to $0.6 \mathrm{M}$, the 4-OH-TEMPO/MV flow cell showed excellent cycling stability (a capacity decay of $0.035 \%$ per cycle over 250 cycles at $80 \mathrm{~mA} \mathrm{~cm}{ }^{-2}$, corresponding to a decay rate of $3.1 \%$ per day), rate performance (a peak power density of $121.6 \mathrm{~mW} \mathrm{~cm}^{-2}$ at $175 \mathrm{~mA} \mathrm{~cm}^{-2}$ ) and a high $\mathrm{CE}$ of $99.7 \%$. Our results suggest that the supporting electrolytes can suppress the parasitic side reactions of nitroxyl radicals, unlike those using aqueous sodium salts as supporting electrolytes. Finally, for the first time, we tested the cell performance of concentrated catholyte with $3 \mathrm{M}$ 4-OH-TEMPO, which delivered a high energy efficiency (EE) of about $65 \%$ at $30 \mathrm{~mA} \mathrm{~cm}$.

\section{Experimental section}

\subsection{Preparation of BMImCl/H $\mathrm{H}_{2}$ Oand $\mathrm{EMImCl} / \mathrm{H}_{2} \mathrm{O}$ solutions with different molalities}

1-butyl-3-methylimidazolium chloride (BMImCl, $\geq 98.0 \%$, Sigma Aldrich) and 1-ethyl-3-methylimidazolium chloride (EMImCl, 97\%, Acros Organics) were used as 
received without further purification. Solutions with different molalities (m, mol kg-1 water, differing from $\mathrm{M}=\mathrm{mol} \mathrm{L}{ }^{-1}$ solution) of imidazolium chlorides were prepared. For instance, to obtain a $3 \mathrm{~m} \mathrm{BMImCl} / \mathrm{H}_{2} \mathrm{O}, 0.524 \mathrm{~g}$ (i.e., $3 \mathrm{mmol}$ ) $\mathrm{BMImCl}$ was added into $1 \mathrm{~g}$ distilled water.

\subsection{Solubility tests of 4-OH-TEMPO and $M V$}

The solubility limits of 4-OH-TEMPO and MV were measured by adding the solid powders into the $\mathrm{BMImCl} / \mathrm{H}_{2} \mathrm{O}$ or $\mathrm{EMImCl} / \mathrm{H}_{2} \mathrm{O}$ until no further solid could be dissolved. The amounts of 4-OH-TEMPO and MV, and the final volume of the solutions were recorded to calculate the final concentration $\left(\mathrm{M}, \mathrm{mol} \mathrm{L}{ }^{-1}\right.$ solution $)$ of the active materials. All the tests were conducted at room temperature.

\subsection{Pretreatment of ion exchange membrane and graphite felt}

The commercial Fumasep ${ }^{\circledR}$ FAA-3-30 anion exchange membrane (thickness: $30 \mu \mathrm{m}$, non-reinforced, dry membrane delivered in bromide form, Fumatech BWT GmbH, Germany) was soaked in $1 \mathrm{M} \mathrm{KOH}$ at $60^{\circ} \mathrm{C}$ for $30 \mathrm{~min}$ and then immersed in $1 \mathrm{M} \mathrm{NaCl}$ for $24 \mathrm{~h}$. Accordingly, the membrane was exchanged into $\mathrm{OH}^{-}$form, then into chloride form. The dimensional change of swelling in length is about $5 \%$ after first step soaking and the membrane size remained afterwards. The pretreated membranes were stored in aqueous imidazolium solutions at room temperature prior to use, and assembled in a cell in wet form. The graphite felt (GFD4.6 EA, Sigracell ${ }^{\circledR}$ Carbon) was first immersed in $1 \mathrm{M} \mathrm{H}_{2} \mathrm{SO}_{4}$ for $24 \mathrm{~h}$ and then thermally treated at $400{ }^{\circ} \mathrm{C}$ for $24 \mathrm{~h}$ in static air.

\subsection{Characterization techniques}

The ionic conductivity of the electrolytes was recorded on a WTW Cond 3110 conductivity meter (Xylem, Germany) at room temperature. The rheological behavior of the solutions was measured on a MCR 301 (Anton Paar GmbH, Graz, Austria) rheometer using a cone-plate (50 mm diameter) measuring system by applying shear rates from 0 to $1500 \mathrm{~s}^{-1}$.

The electron paramagnetic response (EPR) measurements were performed at room temperature using a Magnettech MS5000 Desktop spectrometer operating at $\sim 9.49 \mathrm{GHz}$ (X 
band), $0.3 \mathrm{~mW}$ microwave power with $0.1 \mathrm{mT}$ modulation amplitude at $100 \mathrm{kHz}$. The EPR samples were collected from different states of charge/discharge of a flow cell. The solutions were filled in $50 \mu \mathrm{L}$ micropipettes (Blaubrand ${ }^{\circledR}$ intraMARK) and two ends of the tubes were sealed with paraffin oil. All operations prior to recording the EPR spectra were carried out in an argon-filled glovebox.

The small angle X-ray scattering (SAXS) patterns were performed using a Xenocs Xeuss 2.0 setup, equipped with a $\mathrm{Cu} K_{\alpha}$ source (wavelength, $\lambda=1.54 \AA$ ) and a Pilatus $1 \mathrm{M}$ detector (Dectris, Switzerland). Samples were filled in quartz capillaries and sealed with epoxy. Scattering curves were recorded between 20 and $80{ }^{\circ} \mathrm{C}$ in steps of $5{ }^{\circ} \mathrm{C}$.

\subsection{Electrochemical measurements}

The cyclic voltammetry (CV) tests were conducted using a glassy carbon working electrode (with a diameter of $2 \mathrm{~mm}$ ), a Pt counter electrode and a Ag wire quasi-reference electrode. $\mathrm{CV}$ curves were measured at different potential sweep rates from 10 to $300 \mathrm{mV} \mathrm{s}^{-1}$ at room temperature. For the rotating disk electrode (RDE) measurements (Pine Instruments), $1 \mathrm{mM}$ 4-OH-TEMPO and $1 \mathrm{mM}$ MV in $3 \mathrm{~m} \mathrm{BMImCl} / \mathrm{H}_{2} \mathrm{O}$ were tested with a $5 \mathrm{~mm}$ diameter glassy carbon working electrode, a Pt counter electrode and a Ag reference electrode. The potentials of rotating-electrode were swept between 0.4 and $1.1 \mathrm{~V}$ for 4-OH-TEMPO, 1.2 and $0 \mathrm{~V}$ for $\mathrm{MV}$, respectively, at a sweeping rate of $5 \mathrm{mV} \mathrm{s}^{-1}$ with rotational speeds between 300-2000 rpm. Before the data collection, the electrolytes were purged with Ar gas for $20 \mathrm{~min}$. At each rotation speed, linear sweep voltammetry experiments were repeated three times to acquire averaged limited current. To calculate the limiting current for the second reduction step of $\mathrm{MV}\left(\mathrm{MV}^{+} / \mathrm{MV}^{0}\right)$, the current from the first reduction was subtracted. The diffusion coefficients $\left(D / \mathrm{cm}^{2} \mathrm{~s}^{-1}\right)$ of the active species were determined by using the Levich equation:

$$
i_{\text {lim }}=0.62 n F A C v^{-1 / 6} \omega^{1 / 2} D^{2 / 3} \quad \text { (Equation 1) }
$$

where $i_{\text {lim }}$ is limiting current, $n$ is the number of electrons transferred $(n=1), F$ is the Faraday constant $\left(26.8 \mathrm{Ah} \mathrm{mol}^{-1}\right), A$ is the disk area $\left(0.1963 \mathrm{~cm}^{2}\right), C$ is the concentration of electroactive species $\left(1 \times 10^{-6} \mathrm{~mol} \mathrm{~cm}^{-3}\right), \omega$ is the rotating angular velocity $\left(\mathrm{rad} \mathrm{s}^{-1}\right)$, and $v$ is the kinematic viscosity, which has been determined to be $0.028 \mathrm{~cm}^{2} \mathrm{~s}^{-1}$ for the $3 \mathrm{~m} \mathrm{BMImCl} / \mathrm{H}_{2} \mathrm{O}$. 


\subsection{Flow cell tests}

Flow cell performance was tested by applying constant charge/discharge current using a Bio-logic VMP-300 multichannel potentiostat. A cell comprising endplates, $\mathrm{Cu}$ current collectors, graphite felt electrodes, and a FAA-3-30 anion exchange membrane was assembled. For the room temperature measurements, a home-made flow cell with an active surface area of $4 \mathrm{~cm}^{2}$ was assembled as reported in a previous study [42]. The electrolytes stored in the tanks were pumped through the electrochemical cell using a peristatic pump (ShenChen,

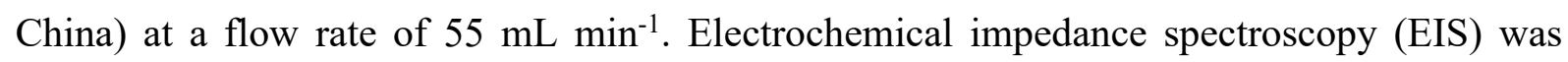
performed at open circuit potential with an amplitude of $10 \mathrm{mV}$ at frequencies ranging between $200 \mathrm{kHz}$ and $100 \mathrm{~m} \mathrm{~Hz}$. Prior to the measurements, the electrolytes were bubbled with Ar gas to reduce the concentration of dissolved oxygen and then sealed with a paraffin oil top-layer.

For high temperature measurements, the electrolytes were heated in an oil bath and then delivered into the electrochemical cell (with an active surface area $6 \mathrm{~cm}^{2}$ ), which was heated to the set temperature. A hole in the graphite bipolar plate allows the insert of a temperature sensor and the monitor of temperature in the reaction area, which was kept at $40 \pm 1{ }^{\circ} \mathrm{C}$.

\subsection{Electrolyte preparation}

Anolyte and catholyte with three different combinations were studied, as summarized in Table 1 . The volumetric energy density was calculated based on the volume of catholyte compartment.

Table 1. Properties of studied electrolytes for flow cell tests.

\begin{tabular}{|c|c|c|c|c|c|c|}
\hline & \multicolumn{3}{|c|}{ Catholyte } & \multicolumn{3}{|c|}{ Anolyte } \\
\hline & $\begin{array}{c}\text { concentration } \\
\text { of } \\
\text { 4-OH-TEMPO }\end{array}$ & $\begin{array}{c}\text { supporting } \\
\text { electrolyte for } \\
\text { 4-OH-TEMPO }\end{array}$ & volume & $\begin{array}{c}\text { concentration } \\
\text { of } \\
\text { MV }\end{array}$ & $\begin{array}{c}\text { supporting } \\
\text { electrolyte for } \\
\text { MV }\end{array}$ & volume \\
\hline (i) & $0.2 \mathrm{M}$ & \multirow[t]{2}{*}{$3 \mathrm{~m} \mathrm{BMImCl} / \mathrm{H}_{2} \mathrm{O}$} & \multirow[t]{2}{*}{$6 \mathrm{~mL}$} & $0.1 \mathrm{M}$ & \multirow[t]{2}{*}{$3 \mathrm{~m} \mathrm{BMImCl} / \mathrm{H}_{2} \mathrm{O}$} & \multirow[t]{2}{*}{$6 \mathrm{~mL}$} \\
\hline (ii) & $0.6 \mathrm{M}$ & & & $0.6 \mathrm{M}$ & & \\
\hline (iii) & $3 \mathrm{M}$ & $3 \mathrm{~m} \mathrm{EMImCl} / \mathrm{H}_{2} \mathrm{O}$ & $5 \mathrm{~mL}$ & $1 \mathrm{M}$ & $3 \mathrm{~m} \mathrm{EMImCl} / \mathrm{H}_{2} \mathrm{O}$ & $15 \mathrm{~mL}$ \\
\hline
\end{tabular}

\section{Results and discussion}


Fig. 1a compares the equivalent electron concentration, namely, the maximum concentration of organic molecules multiplied by the number of electrons transferred, of several representative organic compounds that have been studied in aqueous RFBs $[29,31,32,34,35,41,45-50]$. For the first time, we apply ionic liquid-containing supporting electrolyte for tailoring the properties of redox-active organic materials. In our aqueous ionic liquid supporting electrolytes, the MV and 4-OH-TEMPO showed extremely high solubility of $2.2 \mathrm{M}$ (which is about $2 \mathrm{M}$ in $2 \mathrm{M} \mathrm{NaCl}$ ) and $4.3 \mathrm{M}$ in $3 \mathrm{~m}$ aqueous imidazolium chloride (Fig. 1b), respectively. Two imidazolium groups with slightly different side chain length of $\mathrm{BMIm}^{+}$and $\mathrm{EMIm}^{+}$were used for comparative purposes. To our knowledge, the aqueous solubility of 4.3 M for 4-OH-TEMPO is among the best of all the aqueous catholyte reported for RFBs. This leads to a theoretical volumetric capacity of $115 \mathrm{Ah} \mathrm{L}^{-1}$ with an one-electron transfer reaction, which is about eight times more than that in aqueous $\mathrm{NaCl}$ supporting electrolyte (a solubility of only $0.5 \mathrm{M}$ in $1.5 \mathrm{M} \mathrm{NaCl}$ ) [29]. Note that in pure water, 4-OH-TEMPO has a solubility of 2.1 M [31]. Our approach is distinct from previous work that solubility enhancement is exclusively achieved by chemically grafting functional groups to organic motifs.

To obtain a deeper understanding of the intermolecular interaction between the imidazolium ring from the ionic liquids and the organic solutes, we performed EPR spectroscopy experiments on two series of solutions containing different radical concentrations in 3 and $10 \mathrm{~m} \mathrm{BMImCl} / \mathrm{H}_{2} \mathrm{O}$ (Fig. 1c,1d). EPR is sensitive to probe the averaged magnetic interactions and the motion of radicals in solution, and therefore can be used to clarify the concentration-dependent molecular dynamics and molecular environment in the ternary water/imidazolium/nitroxyl radical system. At lower concentrations $(<0.1 \mathrm{M})$, three reasonably narrow hyperfine lines were observed, indicating that the radicals are highly mobile and not aggregated. As the concentration increases the three lines initially coalesce into a single broad line, which then narrows at the highest concentration. This behavior is typical of enhanced magnetic interactions, e.g. exchange interaction at high concentrations of paramagnetic species. The $10 \mathrm{~m}$ series is slightly narrower than the $3 \mathrm{~m}$ series, illustrating how the increasing amount of BMImCl keeps the 4-OH-TEMPO radicals apart. We conclude that the interaction between the constituent ions of the ionic liquid and the organic radicals (as 
illustrated in Fig. 1e) is stronger than the lattice energy of 4-OH-TEMPO itself, thereby increasing its solubility in electrolytes. In addition, by isolating the 4-OH-TEMPO molecules from each other, the imidazolium cations may also help to stabilize them from collision-caused structural decomposition [45,49], which significantly affects the cycling behavior and capacity retention as will be studied below.

Next, we studied the transport and rheological properties of the supporting electrolytes. Fig. 1f shows the Walden plot of the $\mathrm{BMImCl} / \mathrm{H}_{2} \mathrm{O}$ and $\mathrm{EMImCl} / \mathrm{H}_{2} \mathrm{O}$ with molalities from 3 to 30 $\mathrm{m}$. Both aqueous solutions showed good ionic properties. The latter showed a higher ionic conductivity and lower viscosity, attributed to a shorter alkyl chain. The plot of ionic conductivity versus the molality of the imidazolium chlorides showed a maximum of $58.5 \mathrm{mS}$ $\mathrm{cm}^{-1}$ at $3 \mathrm{~m}$ for the $\mathrm{BMImCl} / \mathrm{H}_{2} \mathrm{O}$, and a maximum of $83.9 \mathrm{mS} \mathrm{cm}-1$ at about $3.5 \mathrm{~m}$ for the $\mathrm{EMImCl} / \mathrm{H}_{2} \mathrm{O}$ (Fig. S1). These values are approaching that $\left(85.7 \mathrm{mS} \mathrm{cm} \mathrm{cm}^{-1}\right)$ of $1 \mathrm{M}$ aqueous $\mathrm{NaCl}$ [14]. The plot of viscosity as a function of the applied shear rate is shown in Fig. S2 . All solutions exhibited Newtonian fluid behavior. The viscosities increased from $1.8 \mathrm{mPa}$ s (3 m EMImCl/ $\mathrm{H}_{2} \mathrm{O}$, compared to $1 \mathrm{mPa}$ s for pure water) to $9.8 \mathrm{mPa} \mathrm{s}\left(10 \mathrm{~m} \mathrm{BMImCl} / \mathrm{H}_{2} \mathrm{O}\right)$. Interestingly, these values are close to those of typical aqueous solutions of $\mathrm{H}_{2} \mathrm{SO}_{4}$ [51] and $\mathrm{NaCl}$ [35]. In addition, the viscosity of the $30 \mathrm{~m} \mathrm{BMImCl} / \mathrm{H}_{2} \mathrm{O}$ reduces from about 43 to 13 $\mathrm{mPa} \mathrm{s}$ by increasing the temperature from 25 to $80{ }^{\circ} \mathrm{C}$. For flow cell tests aiming at a high operating current density, $3 \mathrm{~m}$ imidazolium chloride was therefore chosen as alternative supporting electrolyte owing to its highest ionic conductivity and lowest viscosity.

The influence of the supporting electrolytes on the electrochemical redox properties of 4-OH-TEMPO and MV was studied by the CV experiments (Fig. S3). By using conventional aqueous $\mathrm{NaCl}$ for comparison, a distinct electrochemical behavior of both organic compounds was observed when tested in our supporting electrolytes. In aqueous $\mathrm{NaCl}$ (Fig. 2a, dashed line), 4-OH-TEMPO exhibited a pair of redox peaks at half-wave redox potential $\left(E_{1 / 2}\right)$ of $0.58 \mathrm{~V}$ vs. Ag. Meanwhile, MV exhibited redox reaction at $-0.71 \mathrm{~V}$ vs. Ag corresponding to the $\mathrm{MV}^{2+} / \mathrm{MV}^{+\bullet}$ couple. However, the second reduction process of $\mathrm{MV}^{+\bullet} / \mathrm{MV}^{0}$ showed poor reversibility, consistent with previous observations [29,31,32]. In contrast, in $3 \mathrm{~m}$ $\mathrm{BMImCl} / \mathrm{H}_{2} \mathrm{O}$ (Fig. 2a, solid line), 4-OH-TEMPO showed a higher $E_{1 / 2}$ of $0.71 \mathrm{~V}$ vs. Ag, corresponding to a positive shift of the redox potential of $+0.13 \mathrm{~V}$ for the oxoammonium 
/nitroxyl radical couple, which is beneficial for a higher overall cell voltage. Interestingly, MV showed two consecutive and reversible electron transfer reductions in $3 \mathrm{~m} \mathrm{BMImCl} / \mathrm{H}_{2} \mathrm{O}$ at redox potentials of $-0.54 \mathrm{~V}$ vs. $\mathrm{Ag}\left(\mathrm{MV}^{2+} / \mathrm{MV}^{+\bullet}\right)$ and $-0.90 \mathrm{~V}$ vs. $\mathrm{Ag}\left(\mathrm{MV}^{+\bullet} / \mathrm{MV}^{0}\right)$. Note that $2 \mathrm{e}^{-}$utilization of MV in aqueous electrolytes has been only recently obtained by introducing ammonium functional end groups [47].

Furthermore, CV experiments with variable potential scan rates were performed to study the electrochemical response of both organic materials in $3 \mathrm{~m} \mathrm{BMImCl} / \mathrm{H}_{2} \mathrm{O}$ (Fig. S4,S5). From 10 to $300 \mathrm{mV} \mathrm{s}^{-1}$, both materials showed reversible redox peaks and narrow peak separation, indicating fast reaction rate. A linear relationship between the peak current and the square root of the scan rate was observed for the $1 \mathrm{e}^{-}$reaction of 4-OH-TEMPO and $2 \mathrm{e}^{-}$ reaction of MV, suggesting diffusion-controlled processes. In order to determine the chemical diffusion coefficients for both materials, linear sweep voltammetry (LSV) with a RDE at rotation rates ranging from 300 to $2100 \mathrm{rpm}$ was carried out (Fig. S6). MV underwent two-step redox reactions and 4-OH-TEMPO showed a $1 \mathrm{e}^{-}$redox reaction, in agreement with the $\mathrm{CV}$ results. The diffusion coefficient of 4-OH-TEMPO was calculated as $5.31 \times 10^{-6} \mathrm{~cm}^{2} \mathrm{~s}^{-1}$ from the slope of the linearly fitted Levich plot. Meanwhile, the diffusion coefficients were $7.83 \times 10^{-6}$ and $8.81 \times 10^{-6} \mathrm{~cm}^{2} \mathrm{~s}^{-1}$ for the $1^{\text {st }}$ and $2^{\text {nd }}$ reduction reaction of $\mathrm{MV}$, respectively. Such values are comparable or higher than those for some redox-active molecules determined in acidic solutions $[30,33,36,37,48,52]$.

The electrochemical performance of a flow cell that can utilize the two-electron transfer reactions of MV was studied at first. An all-organic flow cell comprising $0.1 \mathrm{M} \mathrm{MV}$ as anolyte (with an effective electron concentration of $0.2 \mathrm{M}$ ), 0.2 M 4-OH-TEMPO as catholyte, $3 \mathrm{~m} \mathrm{BMImCl} / \mathrm{H}_{2} \mathrm{O}$ as supporting electrolytes, and a FAA-3-30 anion exchange membrane was tested at $40{ }^{\circ} \mathrm{C}$. As shown in Fig. 2b, from 20 to $55 \mathrm{~mA} \mathrm{~cm}{ }^{-2}$ two pairs of well-defined charge/discharge plateaus can be seen, corresponding to the oxoammonium/nitroxyl radical catholyte reaction coupled with $\mathrm{MV}^{2+} / \mathrm{MV}^{+\bullet}$ and $\mathrm{MV}^{+\bullet} / \mathrm{MV}^{0}$ anolyte reactions. Accordingly, the color of electrolyte reversibly changed from colorless at initial state to blue upon one-electron reduction with the formation of $\mathrm{MV}^{+\bullet}$, and then turned into colorless again after the second reduction (Fig. S7), indicating a highly reversible process of $2 \mathrm{e}^{-}$reactions of MV. At $20 \mathrm{~mA} \mathrm{~cm}^{-2}$ the flow cell showed discharge plateaus with average voltages of 1.3 and 1.0 
$\mathrm{V}$, a CE of $99.0 \%$, and a volumetric discharge capacity of $5.1 \mathrm{Ah} \mathrm{L}^{-1}$, (i.e., an energy density of $8 \mathrm{Wh} \mathrm{L}^{-1}$ ). With increasing the current density, the CE remained at about $99.0 \%$, and the voltage efficiency (VE) decreased from $75 \%$ at $20 \mathrm{~mA} \mathrm{~cm}^{-2}$ to $50 \%$ at $55 \mathrm{~mA} \mathrm{~cm}^{-2}$ (Fig. 2c).

Fig. $2 \mathrm{~d}$ shows the cycling performance of the flow cell over 50 cycles at $55 \mathrm{~mA} \mathrm{~cm}^{-2}$ with a discharge capacity of $3.8 \mathrm{Ah} \mathrm{L}^{-1}$ (corresponding to an electrolyte utilization of $71 \%$, or $1.42 \mathrm{e}^{-}$ reaction for the MV anolyte) and a steady CE of $99.0 \%$. A capacity decay rate of $15.8 \%$ per day was observed. It is considered that the chemical instability of the nitroxyl radical can be accelerated at elevated temperatures [53]. In addition, for the low-concentration MV anolyte, its cycling stability is sensitive to the deoxygenation process. The voltage profile maintained well over cycling (inset in Fig. 2d, Fig. S8), indicating sufficient chemical stability and excellent reversibility.

To trace the formation of the viologen radical species in the anolyte over cycling, ex situ EPR spectra were recorded for anolyte at different states of charge/discharge. At stages of "A" and "E" (namely $\mathrm{MV}^{2+}$ species), as labeled in Fig. 3a, the EPR spectra are featureless (Fig. $3 \mathrm{~b}$ ), indicating the absence of radical species in the anolyte. After the first electron transition (stage "B"), a characteristic signal assigned to $\mathrm{MV}^{+\bullet}$ radical was observed, confirming the involvement of the $\mathrm{MV}^{2+} \rightarrow \mathrm{MV}^{+\bullet}$ reaction. Near the end of the second charge plateau (stage "C"), an EPR signal with multiple peaks was observed, which implies the intermolecular interactions among the viologen units [54-56]. When discharging, the intensity of the multiple signal decreased (stage "D", with $\mathrm{MV}^{+\bullet}$ species dominant) and finally vanished at stage "E" $\left(\mathrm{MV}^{2+}\right)$. Those results clearly confirmed the excellent $2 \mathrm{e}^{-}$reversibility of $\mathrm{MV}$ in the applied supporting electrolyte. In order to check if crystallite species and precipitates from viologen were present at stages "B" and especially "C" (with $\mathrm{MV}^{0}$ species dominant), the corresponding anolytes were subjected to SAXS measurements with a heating program from 20 to $80{ }^{\circ} \mathrm{C}$ (Figs. 3c and 3d). There were no scattering peaks for both aliquots, suggesting an attractive dissolution capability of our supporting electrolyte for the neutral $\mathrm{MV}^{0}$ species. Afterwards, the soluble $\mathrm{MV}^{0}$ species can be re-oxidized in the redox electrolytes. In a strong contrast, in aqueous $\mathrm{NaCl}$ the neutral state of $\mathrm{MV}^{0}$ is less reversible and forms participate [47,57]. Additionally, the SAXS profiles maintained well upon heating up to $80^{\circ} \mathrm{C}$, hinting a good thermal stability of the active material and supporting electrolyte. 
To enhance the volumetric energy storage capability, electrolytes with high concentration of active compounds are required in practice. We thus investigated the cyclability, rate performance and cycling stability of a flow cell with $0.6 \mathrm{M}$ 4-OH-TEMPO against $0.6 \mathrm{M} \mathrm{MV}$ at room temperature. We found that if a high upper cutoff voltage $(>1.4 \mathrm{~V})$ was applied, the $2 \mathrm{e}^{-}$reactions of $\mathrm{MV}$ at $0.6 \mathrm{M}$ formed precipitates, resulting in clogging in flow channel. Thus, the galvanostatic charge/discharge of the flow cell was performed at current densities from 20 to $75 \mathrm{~mA} \mathrm{~cm}^{-2}$ and cut-off voltages between 0.6 and $1.4 \mathrm{~V}$ (Fig. 4a). With a $1 \mathrm{e}^{-}$reaction of $\mathrm{MV}$, the flow cell delivered capacity of $15.6,14.2,12.6,11.4$ and $9.2 \mathrm{Ah} \mathrm{L}^{-1}$ at current density of 20,30, 50, 60 and $75 \mathrm{~mA} \mathrm{~cm}^{-2}$, respectively, with a high and constant CE of 99.5\% (Fig. 4b). At $20 \mathrm{~mA} \mathrm{~cm}^{-2}$, a high electrolyte utilization of $96.8 \%$ was observed, indicating nearly complete redox reaction of the active materials. In addition, an average discharge voltage of $1.15 \mathrm{~V}$ was observed, compared to $1 \mathrm{~V}$ for the low concentration electrolyte in Fig. $2 \mathrm{~b}$ at the same current density. Even at $75 \mathrm{~mA} \mathrm{~cm}^{-2}$, a high VE of $70.0 \%$ and $\mathrm{EE}$ of $69.7 \%$ can be still maintained, which are superior to those of previous work using TEMPO-derivatives in aqueous media $(\leq 0.5 \mathrm{M})[29,31,32,58,59]$. At $50 \mathrm{~mA} \mathrm{~cm}{ }^{-2}$, a good capacity retention of $94.2 \%$ over 150 cycles (corresponding to a capacity fade rate of $1.2 \%$ per day) was observed with nearly unchanged voltage profiles (Fig. 4c). Afterwards, anolyte and catholyte were collected for CV measurements to check if cross-mixing occurred (Fig. S9). No detectable redox peaks from 4-OH-TEMPO can be seen from the anolyte, neither peaks from MV can be seen from the catholyte, confirming the low-cost anion exchange membrane is effective to avoid the cross-mixing. In addition, the anolyte of MV kept as liquid feature with $1 \mathrm{e}^{-}$reaction, as expected (Fig. S10).

Considering that the $\mathrm{EMImCl} / \mathrm{H}_{2} \mathrm{O}$ has slightly lower viscosity and higher ionic conductivity compared to the $\mathrm{BMImCl}$ counterpart, the long-term cycling stability and rate performance of 4-OH-TEMPO/MV was also examined in the $3 \mathrm{~m} \mathrm{EMImCl} / \mathrm{H}_{2} \mathrm{O}$ supporting electrolyte at $80 \mathrm{~mA} \mathrm{~cm}^{-2}$ and room temperature. The CE and EE remained around $99.7 \%$ and $60 \%$, respectively, over 250 cycles with excellent capacity retention of $91.2 \%$ (i.e., a decay of $0.035 \%$ per cycle, or $3.1 \%$ per day, Fig. 4d). Surprisingly, such capacity retention is much better than that for 4-OH-TEMPO tested in aqueous $\mathrm{NaCl}(0.3 \%$ decay per cycle, or $12 \%$ per day) [60], and other aqueous $\mathrm{Na}_{2} \mathrm{SO}_{4}$ and $\mathrm{NaClO}_{4}$ (about $0.9 \%$ per cycle) against a metal 
anode [61]. It is considered that the aqueous imidazolium chloride as reaction media may inhibit the unfavorable parasitic side reactions of 4-OH-TEMPO and thus preserve the active material. In addition, previous combinations of organic materials-based electrolytes, neutral $\mathrm{pH}$ value and low-cost anion exchange membranes can hardly been operated at a high current density (general $<40 \mathrm{~mA} \mathrm{~cm}{ }^{-2}$ ) [14]. Fig. 4e shows the polarization curve of the flow cell at approximately $100 \%$ state-of-charge (SOC), exhibiting a peak power density of $121.6 \mathrm{~mW}$ $\mathrm{cm}^{-2}$ at $175 \mathrm{~mA} \mathrm{~cm}$, which is comparable to the one of a previously reported viologen-based RFBs [57], and among the best in neutral $\mathrm{pH}$ aqueous electrolytes.

So far, few organic materials have been demonstrated with a concentration higher than $2 \mathrm{M}$ for RFBs [35,40], By using $3 \mathrm{~m} \mathrm{EMImCl} / \mathrm{H}_{2} \mathrm{O}$ as supporting electrolytes, $3 \mathrm{M}$ 4-OH-TEMPO catholyte $(5 \mathrm{~mL})$ was paired with $1 \mathrm{M}$ MV anolyte $(15 \mathrm{~mL})$. Accordingly, the capacities of catholyte and anolyte were balanced through the use of asymmetric electrolyte volume. The CE increased from $90 \%$ at $25 \mathrm{~mA} \mathrm{~cm}^{-2}$ to $94 \%$ at $30 \mathrm{~mA} \mathrm{~cm}^{-2}$ (Fig. 5a). This indicates that the cross-mixing becomes severer at such a high concentration. At $30 \mathrm{~mA} \mathrm{~cm}{ }^{-2}$, steady VE and EE of $65 \%$ were observed for the flow cell using $3 \mathrm{M}$ catholyte, compared to $86 \%$ in $0.6 \mathrm{M}$ catholyte, due to an increased solution resistance with concentrated electrolyte. The cell resistance increased from $1.92 \Omega \mathrm{cm}^{2}$ for $0.6 \mathrm{M}$ catholyte to $5.12 \Omega \mathrm{cm}^{2}$ for $3 \mathrm{M}$ catholyte, as determined from the electrochemical impedance spectroscopy (Fig. S11). A relatively fast capacity fading $(0.75 \%$ capacity loss per cycle, or $8.2 \%$ per day) and low electrolyte utilization were observed for the concentrated $3 \mathrm{M}$ catholyte at $30 \mathrm{~mA} \mathrm{~cm}{ }^{-2}$ (Fig. S12). Thus, simultaneous optimization of the chemical structure of the active materials [29-41] and the selection of supporting electrolytes is needed to improve the performance for concentrated electrolytes in the future. The polarization curves showed a maximum power density of 65 $\mathrm{mW} \mathrm{cm}^{-2}$ (Fig. 5b). Fig. 5c compares the key performance parameters for organic materials-based aqueous RFBs in term of concentration, cell voltage and power density. Compared to the general chemical modification of organic materials to obtain the TEMPO-, and MV-derivatives [47,57,58,62,63], our work shows an alternative and promsing strategy to optimize the performance of organic materials simply by choosing suitable supporting electrolytes. 


\section{Conclusions}

To summarize, by using $3 \mathrm{~m}$ aqueous imidazolium $\left(\mathrm{BMIm}^{+}\right.$and $\left.\mathrm{EMIm}^{+}\right)$chlorides as supporting electrolytes with high ionic conductivity (a maximum of $83 \mathrm{mS} \mathrm{cm}^{-1}$ ) and water-like flowability (with a minimal viscosity of $1.8 \mathrm{mPa} \mathrm{s}$ ), a record aqueous solubility of 4.3 $\mathrm{M}$ for the commercial 4-OH-TEMPO has been achieved, arising from enhanced intermolecular interactions as studied from EPR measurements. In addition, our supporting electrolytes permit the $2 \mathrm{e}^{-}$reactions of unmodified MV with excellent reversibility and stability, and certain solubility of neutral $\mathrm{MV}^{0}$ species as examined from SAXS experiments. This is distinct from earlier work that $\mathrm{MV}^{0}$ forms precipitation in aqueous $\mathrm{NaCl}$ and shows electrochemical irreversibility. At $0.6 \mathrm{M}$ of $\mathrm{MV}$, only $1 \mathrm{e}^{-}$reaction is possible to maintain a liquid state. For the $0.6 \mathrm{M}$ catholyte and anolyte, excellent cycling stability and rate performance have been observed, which is superior to those from previous work using aqueous sodium salts as supporting electrolytes. It is deduced that our proposed supporting electrolytes as new reaction media for the redox-active organic materials can preserve well their molecular structure by suppressing the side reactions. For the first time, 4-OH-TEMPO catholyte with a high concentration of $3 \mathrm{M}$ was evaluated in a flow cell, which showed a high energy efficiency of $65 \%$ at $30 \mathrm{~mA} \mathrm{~cm}^{-2}$. Our work provides an alternative approach for the design of high performance redox electrolytes. By exploring the potential of compatible supporting electrolytes, the key performance parameters, including solubility, electrochemical reversibility and chemical stability, can be optimized. It is expected that the capacity, cycling stability and power performance can be further improved by optimizing the chemical structure of redox-active materials, selecting suitable ionic liquids [64] and a more conductive membrane, using electrocatalysts and operating the flow cell at elevated temperatures.

\section{Supporting Information}

Supporting Information is available from the Online Library or from the author.

\section{Acknowledgements}

This work was supported by the KIST Europe basic research funding, "new electrolytes for redox flow batteries". R.C. thanks the partial financial support from the CMBlu Energy AG, 
Alzenau, Germany. Z.H. acknowledges support from China CSC Abroad Studying Fellowship. C.W.M.K. acknowledges financial support from the Saarland University. R.C. acknowledges the continuous support from Prof. R. Hempelmann, and Dr. Junkyung Kim. A patent concerning supporting electrolyte for organic materials has been jointly filed by KIST Europe and CMBlu Energy AG (PCT/EP2019/054763, 2019) that names R.C. as the first inventor.

\section{References}

[1] B. Dunn, H. Kamath, J.-M. Tarascon, Science 334 (2011) 928-935.

[2] A.Z. Weber, M.M. Mench, J.P. Meyers, P.N. Ross, J.T. Gostick, Q. Liu, J. Appl. Electrochem. 41 (2011) 1137-1164.

[3] G.L. Soloveichik, Chem. Rev. 115 (2015) 11533-11558.

[4] Z. Song, H. Zhou, Energy Environ. Sci. 6 (2013) 2280-2301.

[5] B. Haeupler, A. Wild, U.S. Schubert, Adv. Energy Mater. 5 (2015) 1402034.

[6] J. Noack, N. Roznyatovskaya, T. Herr, P. Fischer, Angew. Chem. Int. Ed. 54 (2015) 9776-9809.

[7] Y. Ding, C. Zhang, L. Zhang, Y. Zhou, G. Yu, Chem. Soc. Rev. 47 (2017) 69-103.

[8] P. Leung, A. Shah, L. Sanz, C. Flox, J. Morante, Q. Xu, M. Mohamed, C.P. de León, F. Walsh, J. Power Sources 360 (2017) 243-283.

[9] Y. Liang, Y. Jing, S. Gheytani, K.-Y. Lee, P. Liu, A. Facchetti, Y. Yao, Nature Mater. 16 (2017) 841.

[10] X. Wei, W. Pan, W. Duan, A. Hollas, Z. Yang, B. Li, Z. Nie, J. Liu, D. Reed, W. Wang, ACS Energy Lett. 2 (2017) 2187-2204.

[11] H. Chen, G. Cong, Y.-C. Lu, J. Energy Chem. 27 (2018) 1304-1325.

[12] R. Ye, D. Henkensmeier, S.J. Yoon, Z. Huang, D.K. Kim, Z. Chang, S. Kim, R. Chen, J. Electrochem. En. Conver. Stor. 15 (2018) 010801.

[13] C. Zhang, L. Zhang, Y. Ding, S. Peng, X. Guo, Y. Zhao, G. He, G. Yu, Energy Stor. Mater. 15 (2018) 324-350.

[14] R. Chen, ChemElectroChem 6 (2019) 603-612.

[15] T. Janoschka, N. Martin, U. Martin, C. Friebe, S. Morgenstern, H. Hiller, M.D. Hager, U.S. Schubert, Nature 527 (2015) 78.

[16] M. Duduta, B. Ho, V.C. Wood, P. Limthongkul, V.E. Brunini, W.C. Carter, Y.M. Chiang, Adv. Energy Mater. 1 (2011) 511-516.

[17] H. Chen, Y.-C. Lu, Adv. Energy Mater. 6 (2016) 1502183.

[18] Q. Huang, J. Yang, C.B. Ng, C. Jia, Q. Wang, Energy Environ. Sci. 9 (2016) 917-921.

[19] Y.G. Zhu, Y. Du, C. Jia, M. Zhou, L. Fan, X. Wang, Q. Wang, J. Am. Chem. Soc. 139 (2017) 6286-6289.

[20] R. Yan, Q. Wang, Adv. Mater. 30 (2018) 1802406.

[21] M.H. Chakrabarti, F.S. Mjalli, I.M. AlNashef, M.A. Hashim, M.A. Hussain, L. Bahadori, C.T.J. Low, Renew. Sust. Energ. Rev. 30 (2014) 254-270. 
[22] K. Takechi, Y. Kato, Y. Hase, Adv. Mater. 27 (2015) 2501-2506.

[23] Y. Yamada, K. Usui, K. Sodeyama, S. Ko, Y. Tateyama, A. Yamada, Nature Energy 1 (2016) 16129.

[24] G. Cong, Y. Zhou, Z. Li, Y.-C. Lu, ACS Energy Lett. 2 (2017) 869-875.

[25] A. Shimizu, K. Takenaka, N. Handa, T. Nokami, T. Itoh, J.I. Yoshida, Adv. Mater. 29 (2017) 1606592.

[26] Y. Yamada, J. Wang, S. Ko, E. Watanabe, A. Yamada, Nature Energy 4 (2019) 269-280.

[27] C. Zhang, Y. Qian, Y. Ding, L. Zhang, X. Guo, Y. Zhao, G. Yu, Angew. Chem. Int. Ed. 58 (2019) 1-7.

[28] J. Huang, L. Cheng, R.S. Assary, P. Wang, Z. Xue, A.K. Burrell, L.A. Curtiss, L. Zhang, Adv. Energy Mater. 5 (2015) 1401782.

[29] J. Luo, B. Hu, M. Hu, Y. Zhao, T.L. Liu, ACS Energy Lett. 4 (2019) 2220-2240.

[30] M.R. Gerhardt, L. Tong, R. Gómez - Bombarelli, Q. Chen, M.P. Marshak, C.J. Galvin, A. Aspuru-Guzik, R.G. Gordon, M.J. Aziz, Adv. Energy Mater. 7 (2017) 1601488.

[31] T. Liu, X. Wei, Z. Nie, V. Sprenkle, W. Wang, Adv. Energy Mater. 6 (2016) 1501449.

[32] X. Wei, L. Cosimbescu, W. Xu, J.Z. Hu, M. Vijayakumar, J. Feng, M.Y. Hu, X. Deng, J. Xiao, J. Liu, Adv. Energy Mater. 5 (2015) 1400678.

[33] Z. Yang, L. Tong, D.P. Tabor, E.S. Beh, M.A. Goulet, D. De Porcellinis, A. Aspuru-Guzik, R.G. Gordon, M.J. Aziz, Adv. Energy Mater. 8 (2018) 1702056.

[34] J. Zhang, Z. Yang, I.A. Shkrob, R.S. Assary, S.o. Tung, B. Silcox, W. Duan, J. Zhang, C.C. Su, B. Hu, Adv. Energy Mater. 7 (2017) 1701272.

[35] T. Janoschka, N. Martin, M.D. Hager, U.S. Schubert, Angew. Chem. Int. Ed. 55 (2016) 14427-14430.

[36] B. Huskinson, M.P. Marshak, C. Suh, S. Er, M.R. Gerhardt, C.J. Galvin, X. Chen, A. Aspuru-Guzik, R.G. Gordon, M.J. Aziz, Nature 505 (2014) 195-198.

[37] K. Lin, Q. Chen, M.R. Gerhardt, L. Tong, S.B. Kim, L. Eisenach, A.W. Valle, D. Hardee, R.G. Gordon, M.J. Aziz, Science 349 (2015) 1529-1532.

[38] J. Winsberg, C. Stolze, A. Schwenke, S. Muench, M.D. Hager, U.S. Schubert, ACS Energy Lett. 2 (2017) 411-416.

[39] J. Huang, L. Su, J.A. Kowalski, J.L. Barton, M. Ferrandon, A.K. Burrell, F.R. Brushett, L. Zhang, J. Mater. Chem. A 3 (2015) 14971-14976.

[40] Z. Chang, D. Henkensmeier, R. Chen, J. Power Sources 418 (2019) 11-16.

[41] A. Hollas, X. Wei, V. Murugesan, Z. Nie, B. Li, D. Reed, J. Liu, V. Sprenkle, W. Wang, Nature Energy 3 (2018) 508.

[42] Z. Huang, P. Zhang, X. Gao, D. Henkensmeier, S. Passerini, R. Chen, ACS Appl. Energy Mater. 5 (2019) 3773-3779.

[43] A. Tatlisu, Z. Huang, R. Chen, ChemSusChem 11 (2018) 3899-3904.

[44] R. Chen, R. Hempelmann, Electrochem. Commun.70 (2016) 56-59.

[45] E. S. Beh, D. De Porcellinis, R. L. Gracia, K. T. Xia, R. G. Gordon, M. J. Aziz, ACS Energy Lett. 2 (2017) 639-644.

[46] S. Jin, Y. Jing, D.G. Kwabi, Y. Ji, L. Tong, D. De Porcellinis, M.-A. Goulet, D.A. Pollack, R.G. Gordon, M.J. Aziz, ACS Energy Lett. 4 (2019) 1342-1348.

[47] C. DeBruler, B. Hu, J. Moss, X. Liu, J. Luo, Y. Sun, T.L. Liu, Chem 3 (2017) 961-978. 
[48] W. Liu, Y. Liu, H. Zhang, C. Xie, L. Shi, Y.-G. Zhou, X. Li, Chem. Commun. 55 (2019) 4801-4804.

[49] M.-A. Goulet, L. Tong, D.A. Pollack, D.P. Tabor, E.E. Kwan, A. Aspuru-Guzik, R.G. Gordon, M.J. Aziz, J. Am. Chem. Soc. 141 (2019) 8014-8019.

[50] K. Lin, R. Gómez-Bombarelli, E.S. Beh, L. Tong, Q. Chen, A. Valle, A. Aspuru-Guzik, M.J. Aziz, R.G. Gordon, Nature Energy 1 (2016) 16102.

[51] M. Skyllas-Kazacos, L. Cao, M. Kazacos, N. Kausar, A. Mousa, ChemSusChem 9 (2016) 1521-1543.

[52] C. Zhang, Z. Niu, S. Peng, Y. Ding, L. Zhang, X. Guo, Y. Zhao, G. Yu, Adv. Mater. 31 (2019) 1901052.

[53]M. V. Ciriano, H.-G. Korth, W. B. van Scheppingen, P. Mulder, J. Am. Chem. Soc. 121 (1999) 6375.

[54] M.R. Geraskina, A.S. Dutton, M.J. Juetten, S.A. Wood, A.H. Winter, Angew. Chem. Int. Ed. 129 (2017) 9563-9567.

[55] D.E. Clarke, M. Olesińska, T. Mönch, B. Schoenaers, A. Stesmans, O.A. Scherman, Chem. Commun. 55 (2019) 7354-7357.

[56] A.T. Buck, J.T. Paletta, S.A. Khindurangala, C.L. Beck, A.H. Winter, J. Am. Chem. Soc. 135 (2013) 10594-10597.

[57] B. Hu, Y. Tang, J. Luo, G. Grove, Y. Guo, T.L. Liu, Chem. Commun. 54 (2018) 6871-6874.

[58] C. DeBruler, B. Hu, J. Moss, J. Luo, T.L. Liu, ACS Energy Lett. 3 (2018) 663-668.

[59] J. Luo, B. Hu, C. Debruler, T.L. Liu, Angew. Chem. Int. Ed. 57 (2018) 231-235.

[60] Z. Chang, D. Henkensmeier, R. Chen, ChemSusChem 10 (2017) 3193-3197.

[61] A. Orita, M. Verde, M. Sakai, Y. Meng, J. Power Sources 321 (2016) 126-134.

[62] Y. Liu, M.-A. Goulet, L. Tong, Y. Liu, Y. Ji, L. Wu, R.G. Gordon, M.J. Aziz, Z. Yang, T. $\mathrm{Xu}$, Chem 5 (2019) 1861-1870.

[63] J. Luo, B. Hu, C. Debruler, Y. Bi, Y. Zhao, B. Yuan, M. Hu, W. Wu, T.L. Liu, Joule, 3 (2018) 149-163.

[64]L. Wylie, Z. L. Seeger, A. N. Hancock, E. I. Izgorodina, Phys. Chem. Chem. Phys. 21 (2019) 2882. 

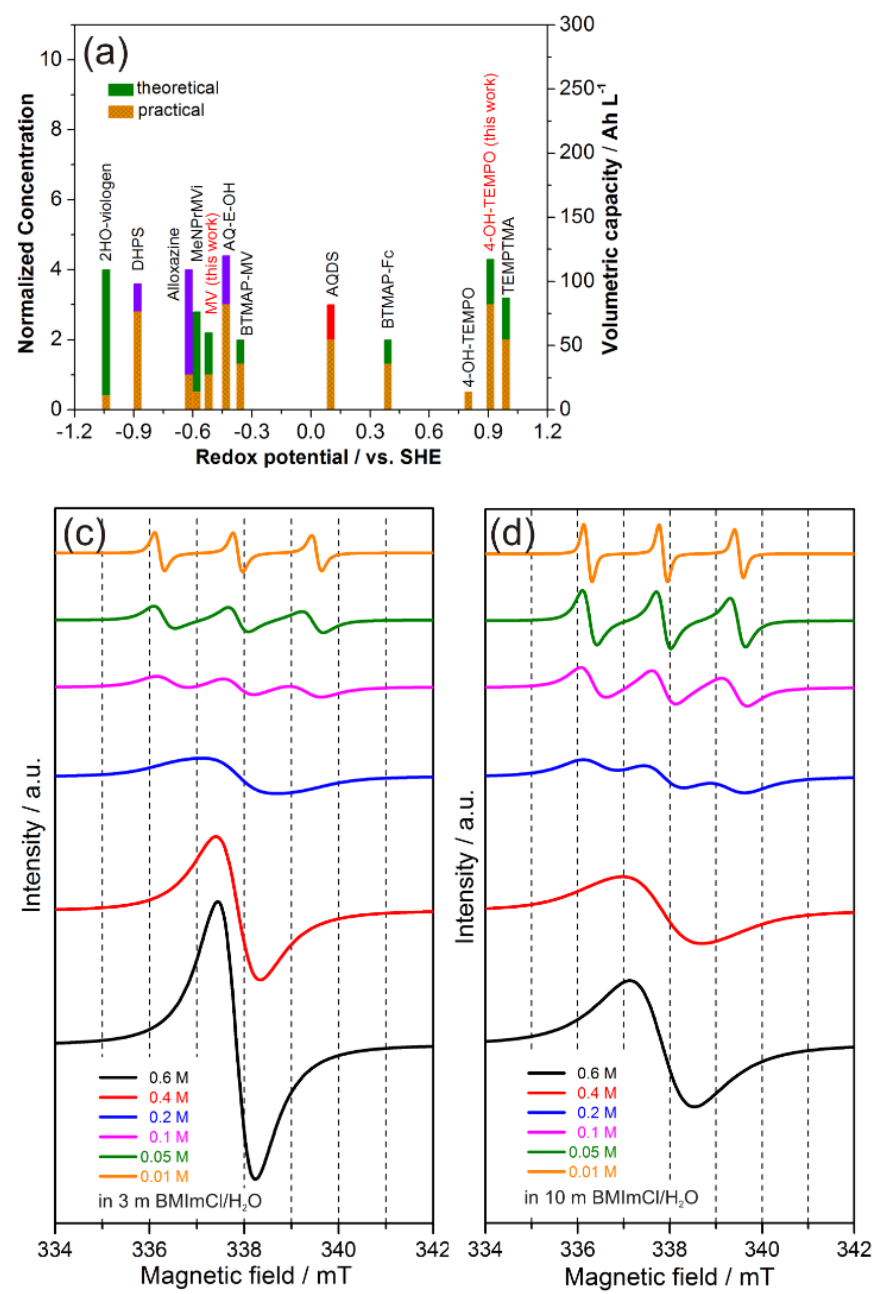

(b)
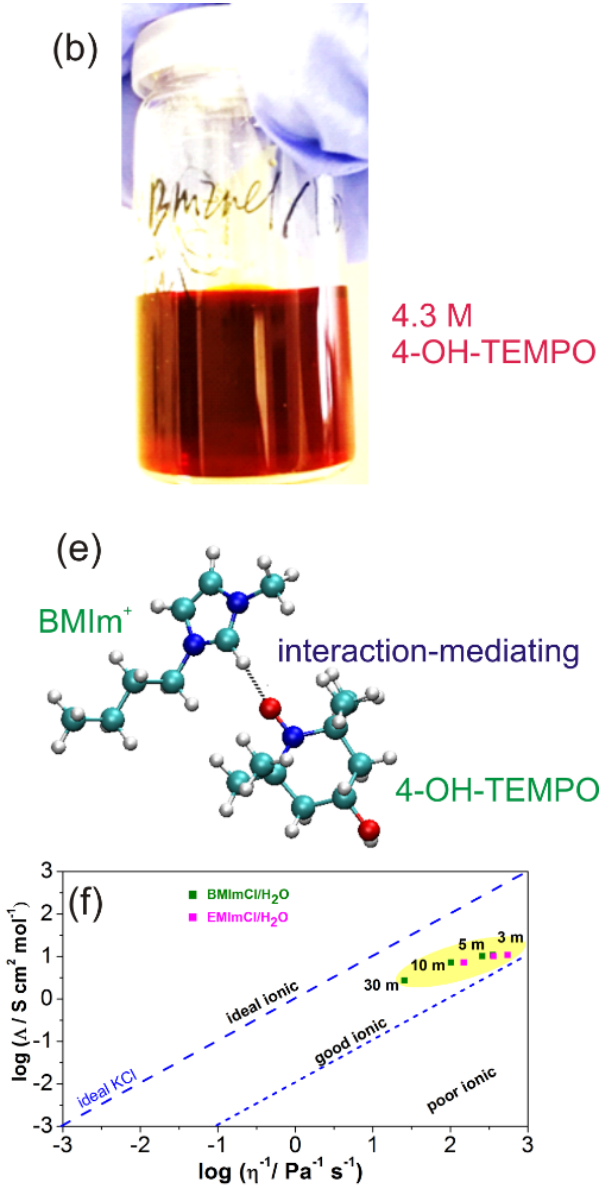

Fig. 1. (a) Comparison of the equivalent electron concentration and volumetric capacity of representative organic molecules for aqueous RFBs, from left to right: 2HO-viologen: (1,1')-di(2-ethanol)-4,4'-bipyridinium dibromide

[48],

DHPS: 7,8-dihydroxyphenazine-2-sulfonic acid [41],

Alloxazine [50], MeNPrMVi:1-methyl-1'-[3-(trimethylammonlo)propyl]-4-4'-bipridinium trichloride [47], AQ-E-OH:1,8-bis(2-(2-(2-hydroxyethoxy)ethoxyl)ethoxyl)anthracene-9,10-dione [46], BTMAP-MV: bis(3-trimethylammonio)propyl viologen tetrachloride [45], AQDS: 9,10-Anthraquinone-2,7-dissulphonic acid [36], BTMAP-Fc: bis(3-trimethylammonio)propyl viologen tetrachloride)-ferrocene dichloride [45], 4-OH-TEMPO [31], TEMPMA: N,N,N-2,2,6,6-hexatamethylpiperidinayl oxy-4-ammonium chloride [35]; The color of red, green, and purple represents acidic, neutral, and basic media, respectively. (b) Photograph of a solution containing $4.3 \mathrm{M}$ 4-OH-TEMPO in $3 \mathrm{~m} \mathrm{BMImCl} / \mathrm{H}_{2} \mathrm{O}$ at room temperature. (c,d) EPR spectra of 4-OH-TEMPO with different concentrations in 3 and $10 \mathrm{~m} \mathrm{BMImCl} / \mathrm{H}_{2} \mathrm{O}$, respectively. (e) Schematic illustration of the interactions between the imidazolium group and the organic solute. (f) Walden plot of the aqueous imidazolium chlorides with different molalities. 

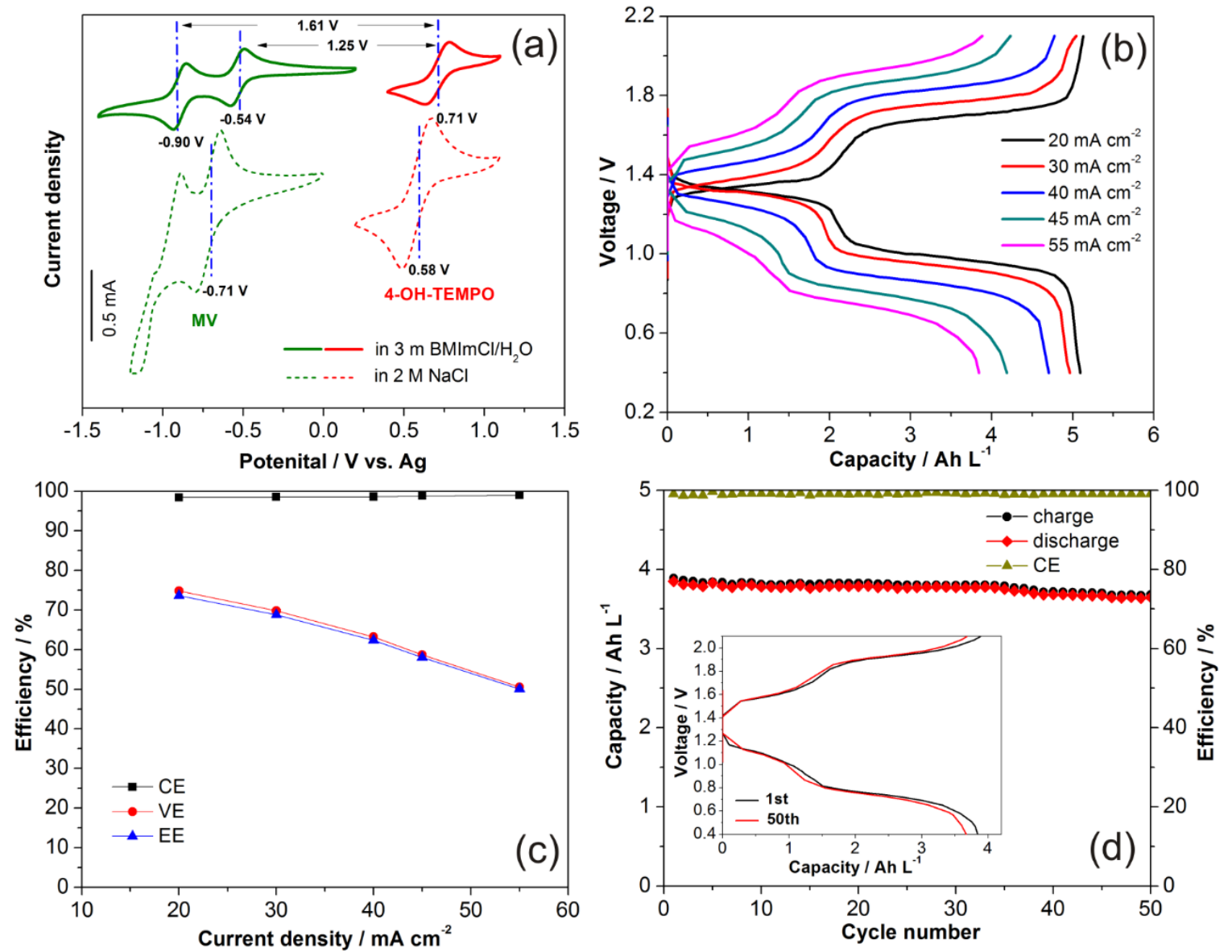

Fig. 2. (a) CV curves of $\mathrm{MV}$ and 4-OH-TEMPO ( $7 \mathrm{mM}$ for both) in different supporting electrolytes of $3 \mathrm{~m} \mathrm{BMImCl} / \mathrm{H}_{2} \mathrm{O}$ (solid line) and $2 \mathrm{M} \mathrm{NaCl}$ (dashed line) at $100 \mathrm{mV} \mathrm{s}^{-1}$, (b-d) Electrochemical performance of a MV $(0.1 \mathrm{M}) / 4-\mathrm{OH}-\mathrm{TEMPO}(0.2 \mathrm{M})$ flow cell (both in $3 \mathrm{~m}$ $\mathrm{BMImCl} / \mathrm{H}_{2} \mathrm{O}$ ) measured at $40{ }^{\circ} \mathrm{C}$, (b) Voltage profiles, (c) the corresponding cycling efficiencies at different current densities, (d) Cycling stability and CE at $55 \mathrm{~mA} \mathrm{~cm}^{-2}$ over 50 cycles. Inset in (d) shows the voltage profiles for the $1^{\text {st }}$ and $50^{\text {th }}$ cycles. 

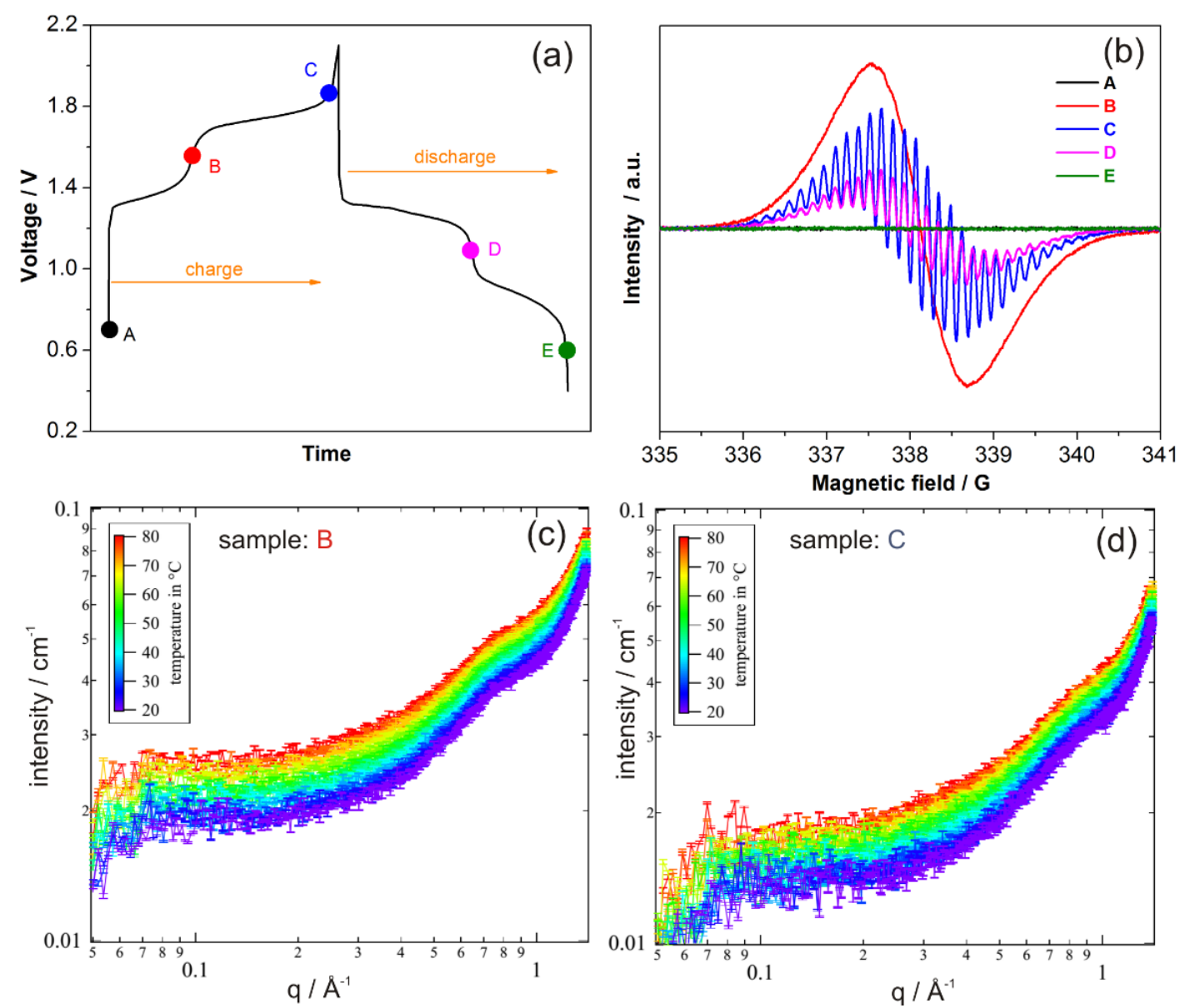

Fig. 3. Reversible $2 \mathrm{e}^{-}$reaction of $0.1 \mathrm{M}$ MV. (a) Samples collected from the anolyte at different states of charge/discharge at room temperature, (b) the corresponding EPR spectra. SAXS profiles with the (c) first and (d) second electron transfer reactions over heating from 20 to $80^{\circ} \mathrm{C}$. 

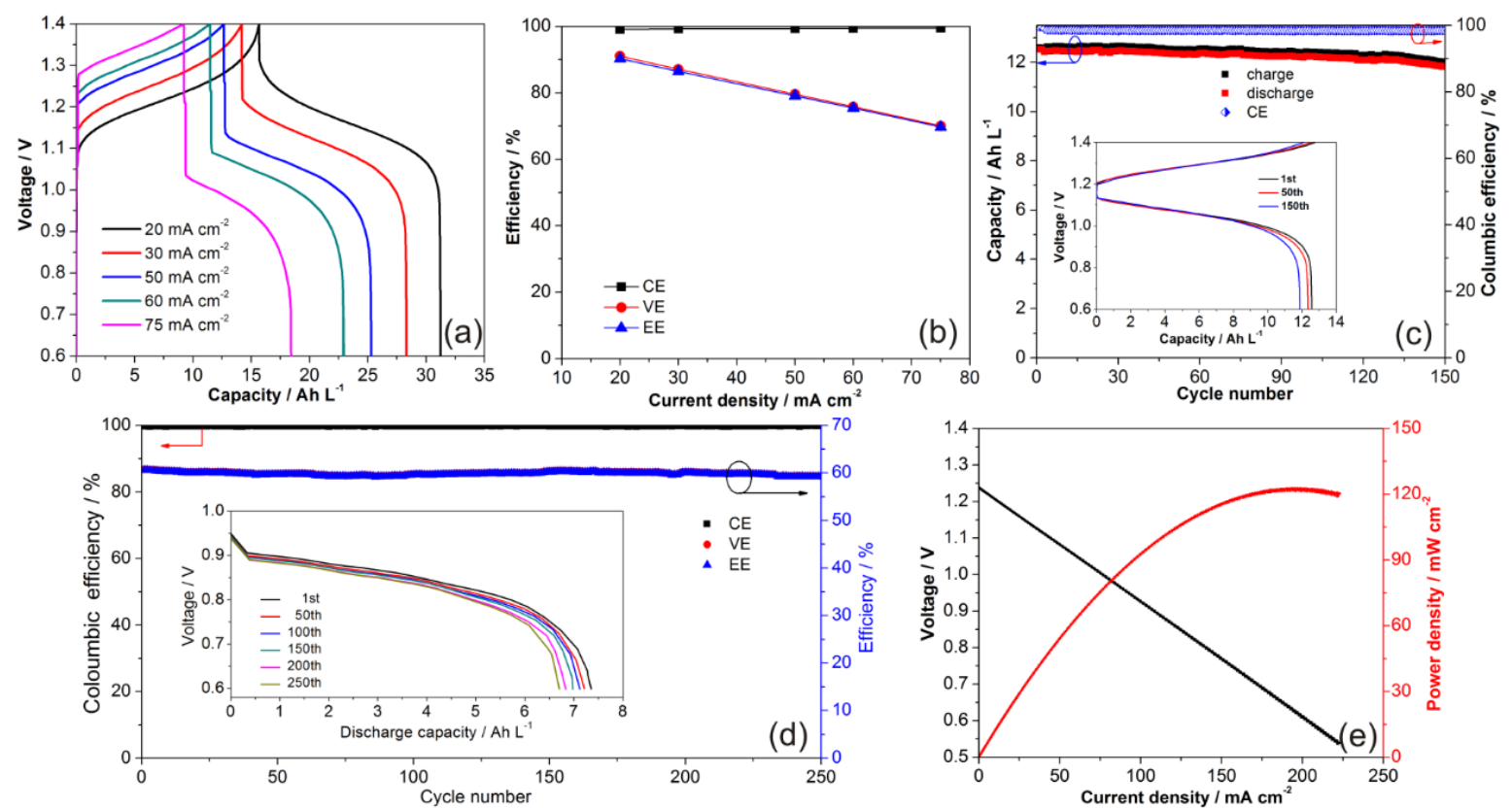

Fig. 4. Electrochemical performance of a flow cell with $0.6 \mathrm{M}$ 4-OH-TEMPO/ 0.6 M MV measured at room temperature. (a) Voltage profiles, and (b) the corresponding efficiencies at different current densities, Cycling stability and efficiencies of the flow cell (c) at $50 \mathrm{~mA} \mathrm{~cm}{ }^{-2}$ over 150 cycles in $3 \mathrm{~m} \mathrm{BMImCl} / \mathrm{H}_{2} \mathrm{O}$, and (d) at $80 \mathrm{~mA} \mathrm{~cm}$ cmer $^{-2}$ ove cycles in $3 \mathrm{~m}$ EMImCl/ $\mathrm{H}_{2} \mathrm{O}$, Inset in (d) shows the discharge curves at different cycles, (e) Polarization and power density curves of the flow cell in $3 \mathrm{~m} \mathrm{EMImCl} / \mathrm{H}_{2} \mathrm{O}$. 

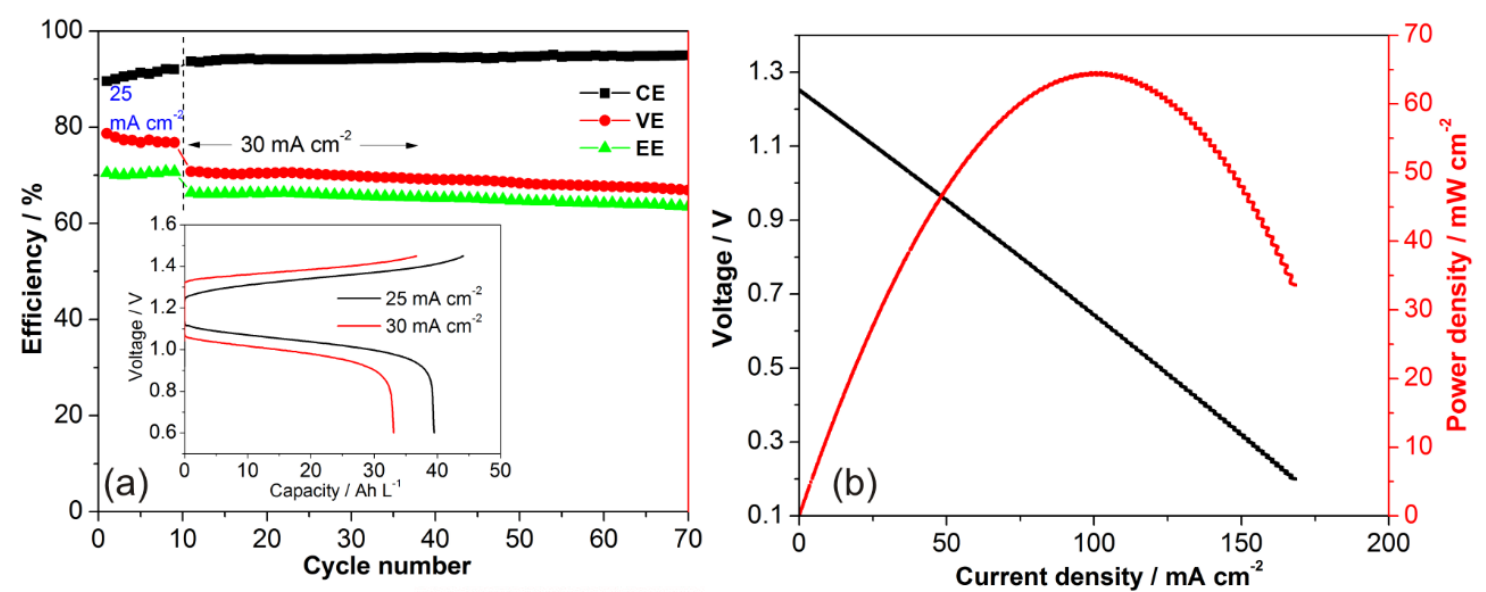

(c)

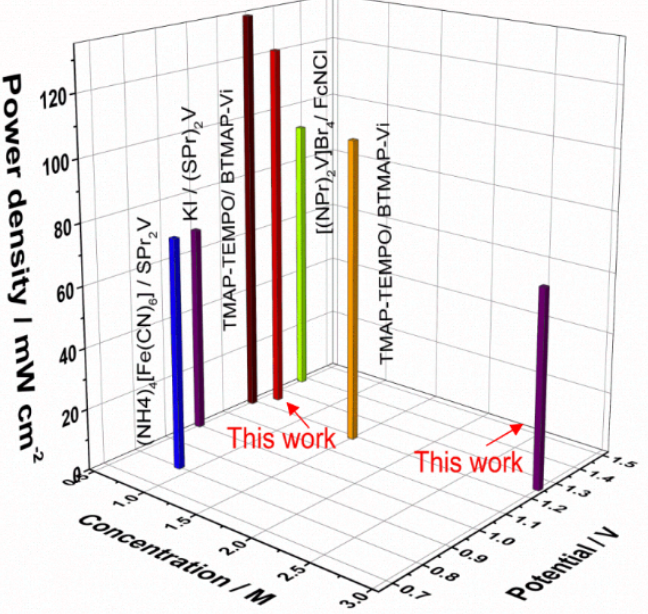

Fig. 5. (a) Cycling efficiencies of a flow cell using $3 \mathrm{M}$ catholyte over 70 cycles between 0.6 and $1.45 \mathrm{~V}$ measured at room temperature, (b) Polarization and power density curves of the flow cell, (c) Comparison of the reported power density, concentration and working potential: $\left[(\mathrm{NPr})_{2} \mathrm{~V}\right] \mathrm{Br}_{4} / \mathrm{FcNCl} \quad[47], \quad \mathrm{KI} /(\mathrm{SP})_{2} \mathrm{~V} \quad$ [58], TMAP-TEMPO/BTMAP-Vi [62], $\left(\mathrm{NH}_{4}\right)_{4}\left[\mathrm{Fe}(\mathrm{CN})_{6}\right] /(\mathrm{SP})_{2} \mathrm{~V}[63]$. 